\title{
A community based study of the incidence of dementia in subjects aged 85 years and over
}

\author{
J Gussekloo, T J Heeren, G J Izaks, G J Ligthart, H G M Rooijmans
}

\begin{abstract}
The aim was to investigate the incidence rate of dementia for community residents aged 85 years and over.

It was a two wave community study of 224 subjects (community residents including those residing in a nursing home) older than 85 years, restudied $4 \cdot 1$ years after a community prevalence study. A two stage method was used, comprising the mini mental state examination followed in a stratified sample by the geriatric mental state schedule (A3)/AGECAT. Incidence rates were based on person-years at risk.

The overall incidence of dementia was 6.9 (95\% confidence interval (95\% CI) 4.8-9.1) per 100 person-years at risk. The incidence was significantly higher for women than for men; respectively 8.9 (95\% CI 5.9-11.9) v 2.7 (95\% CI 0.5-4.9) per 100 person-years at risk.

In the fastest growing age group seven out of 100 persons develop dementia each year. Women, who constitute two thirds of the oldest old, seem to have a higher risk. Further research is needed into the risk factors for dementia in this age group.
\end{abstract}

$(\Im$ Neurol Neurosurg Psychiatry 1995;59:507-510)

Keywords: incidence; dementia; elderly; epidemiology

Dementia is a major source of illness and disability in elderly people. It is a rapidly growing health and social problem, not only because of the fast growth of the elderly population, but especially because of the increasing proportion of people aged 85 years and over among them. Studies of the prevalence of dementia in different age groups have shown a steady increase with age, nearly doubling every five years. ${ }^{1}$ A recent meta-analysis of prevalence studies of dementia found an increase from $1 \%$ in those aged 65 to 69 years, to $22 \%$ in people aged 85 to 89 years, to $35 \%$ for the age group of 95 to 99 years old. ${ }^{2}$ Prevalence rates of dementia give important information about the needs for health care planning. Dementia is a persistent condition, however, which shortens life expectancy, so it is difficult to extrapolate from prevalence only to future needs. Combination with incidence per age group - and still better, factors that influence changes in incidence-is necessary to estimate the relative growth of the number of demented subjects in the future. The incidence of dementia, however, has been studied less often, especially in the older age groups. Incidence studies are more difficult than prevalence studies, because two measurements in time are needed. Especially in the very old loss to follow up due to death is a difficult problem.

The study reported here is a follow up of the prevalence study carried out in the "Leiden 85 plus study" 3 ; it was to estimate the incidence of dementia in community residents aged 85 years and over. The medical ethics committee of Leiden University Hospital approved the study.

\section{Methods}

PREVALENCE STUDY

The "Leiden 85 plus study", a two phase community based survey of the psychiatric morbidity in the oldest old, ${ }^{34}$ was carried out between December 1986 and June 1989.

\section{Phase I}

In the first phase of the study an extensive medical history was taken, routine blood analysis was performed, and the mini mental state examination (MMSE) ${ }^{56}$ and the general health questionnaire (GHQ, 12 item version) ${ }^{7}$ were given. The Leiden population of 85 years and over alive on 1 December 1986 consisted of 1259 people of whom 103 (8\%) were nursing home residents; 222 died before they could be interviewed. Of the remainder, 60 refused to participate and 86 were too ill to be interviewed, which resulted in a response of $86 \%(891 / 1037)$. A verbal consent procedure has been used.

\section{Phase II}

In the second phase of the prevalence study all subjects with either a MMSE score 23 or below or a GHQ score of 3 or above were interviewed by a psychiatrist $(\mathrm{TJH})$, using the Dutch version of the geriatric mental state schedule (GMS). ${ }^{8}$ Diagnoses were based on DSM-III criteria. ${ }^{9}$ Severity of dementia was measured with the clinical dementia rating (CDR). ${ }^{10}$

Of those with an MMSE score $\leqslant 23$ ( $n=$ 311), 49 were diagnosed as not having dementia. Of those who had an MMSE score above $23(n=580)$ a random sample of 42 subjects had been included in the second phase. In this group one subject had possible dementia and three had questionable dementia; seven subjects refused further participa- 


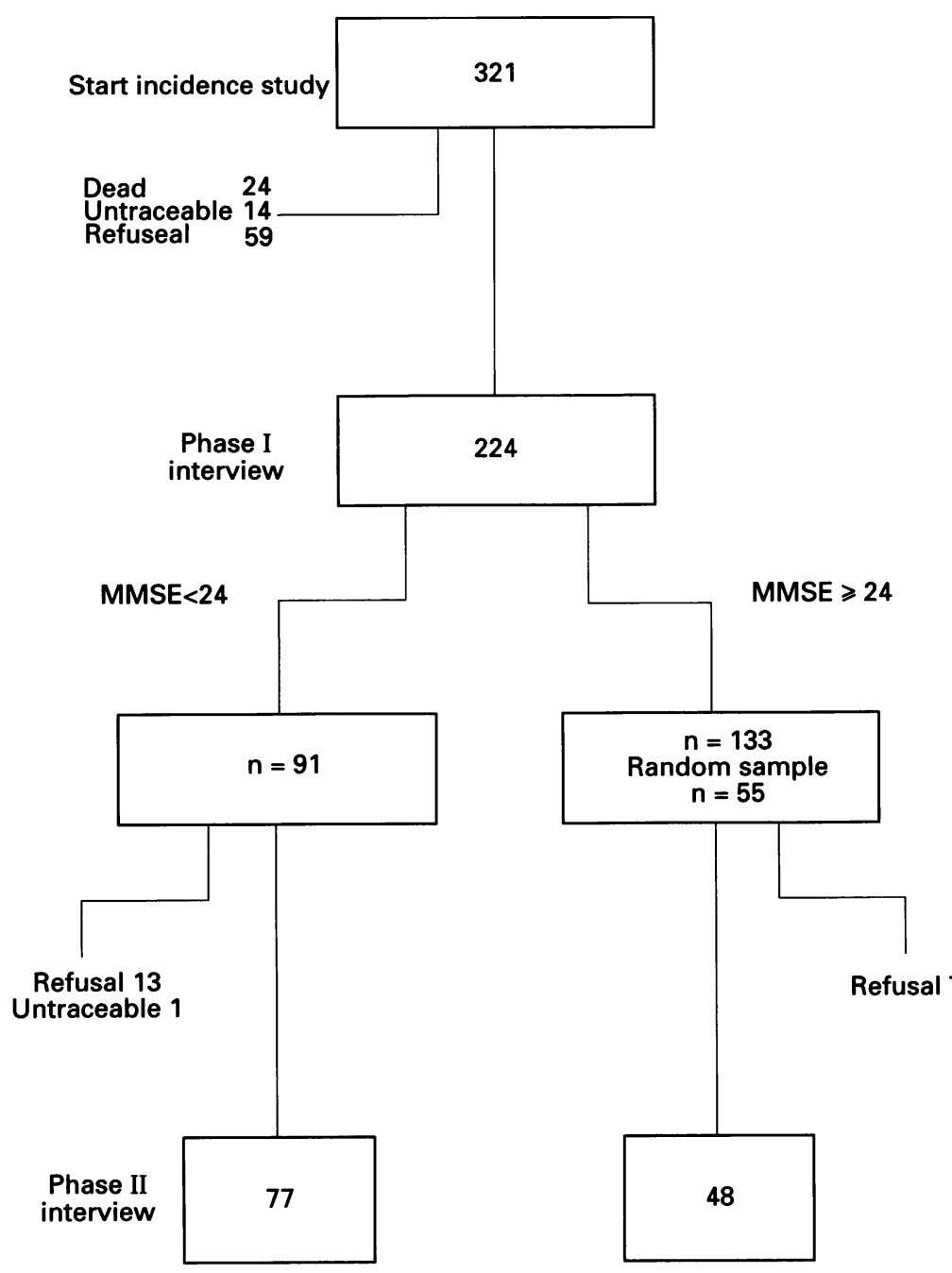

Recruitment of subjects for the incidence study.

tion. The remaining 569 subjects were assumed to be non-demented and eligible for follow up.

\section{INCIDENCE STUDY}

The incidence study was carried out between March and November 1992, a mean of 4.1 (SD 0.4 ) years later. The population at risk for developing dementia included 618 subjects $(49+569)$. On 1 March 1992, 297 subjects at risk had died (48\%), leaving 321 to be interviewed. Again verbal consent was given by the participants.

\section{Phase I}

In phase I participants were interviewed by three trained medical students who took a short medical history and administered the MMSE. The total MMSE score was computed while using only the serial sevens as had been done in the prevalence study. Those who scored below 24 points were included in the second phase.

In addition, a random sample $(n=55)$ of those with an MMSE score $\geqslant 24$ were also included in phase II to estimate the number of dementia cases missed by using the chosen cut off score.
Phase II

In phase II participants were interviewed by a medical doctor (JG) using the Dutch version of the geriatric mental state schedule-abbreviated (third version)/AGECAT, a short community version of the geriatric mental state schedule (GMS).$^{81112}$

The computerised diagnostic system AGECAT identifies syndrome cases or subcases of "organicity", depression, and other psychiatric diagnoses at six levels of confidence. Level 0 represents no syndrome, levels 1 and 2 are regarded as subclinical syndromes or subcases, and levels 3 and above correspond to clinical cases. In this study, those with a level of organicity of 3 or above were considered to be cases of dementia. To reduce the possibility of information bias, the interviewer did not know the previously assessed MMSE scores.

\section{ESTIMATION OF THE INCIDENCE RATE OF DEMENTIA}

The incidence of dementia was estimated as the number of new cases of dementia divided by the number of person-years at risk.

The number of new cases of dementia in the initial population of the incidence study was calculated by summation of the number of new cases found in both MMSE subgroups (MMSE < 24, MMSE $\geqslant 24$ in phase II, multiplied by the reciprocal of the respective sampling fractions.

Person-years at risk for non-cases were calculated as the period between the MMSE screening in the prevalence study and the MMSE screening in the incidence study. For the demented, the date of onset of dementia was assumed to be halfway between the screening interviews and person-years were calculated accordingly.

\section{NON-PARTICIPANTS}

To have some information about the presence of dementia in the group of non-participants (caused by death or refusal), data were gathered from the committee for institutional psychogeriatic care of the region of Leiden. This committee evaluates in a standard way all residents of the region of Leiden who are reported to be in need of institutional psychogeriatric care.

\section{Results}

\section{SAMPLE CHARACTERISTICS}

Of those who were alive at the start of the incidence study $(n=321), 24$ subjects died before they could be interviewed, 14 could not be traced, and 59 refused participation (figure). Finally, 224 subjects were interviewed in phase I (response $70 \%$ ). Seventy per cent were women: $83 \%$ were between 90 and 94 years of age at the entry of the incidence study ( $1 \%$ were $<90$ and $16 \% \geqslant 95$ ). Comparison of the $321(297+24)$ subjects who died before they could be interviewed in the incidence study with those who participated showed that those who died had a higher mean age $(89.8 v 88.9, t$ test, 
Outcome of phase II in the two MMSE subgroups and estimation of the number of dementia cases referred to the total population in phase I

\begin{tabular}{|c|c|c|c|c|c|c|}
\hline & \multicolumn{2}{|c|}{$M M S E<24$} & \multicolumn{2}{|c|}{$M M S E \geqslant 24$} & \multicolumn{2}{|c|}{ Total phase I } \\
\hline & $n$ & $P Y^{*}$ & $n$ & $P Y^{\star}$ & $n$ & $P Y \dagger$ \\
\hline $\begin{array}{l}\text { Demented } \\
\text { Non-demented } \\
\text { Total } \\
\text { Sampling fraction }\end{array}$ & $\begin{array}{l}43 \\
34 \\
77 \\
77 / 91\end{array}$ & $\begin{array}{r}90 \cdot 1 \\
136 \cdot 1 \\
226 \cdot 1\end{array}$ & $\begin{array}{l}2 \\
46 \\
48 \\
48 / 133\end{array}$ & $\begin{array}{r}4.0 \\
191.0 \\
195.0\end{array}$ & $\begin{array}{l}56 \cdot 4 \\
167 \cdot 6 \\
224\end{array}$ & $\begin{array}{l}117 \cdot 6 \\
690 \cdot 0 \\
807 \cdot 5\end{array}$ \\
\hline
\end{tabular}

$\star \mathrm{PY}=$ person-years at risk.

fTotal weighted person-years calculated with use of the sampling fractions of both groups.

$\mathbf{P}<0.001)$, were less often living independently $\left(41 \% v 67 \%, \chi^{2}, \mathrm{P}<0.001\right)$, and had a lower median MMSE score (27 $v 29$, MannWhitney Wilcoxon rank test, $\mathrm{P}<0.001$ ) at the start of the prevalence study.

Significantly more of those who died were indicated for institutional psychogeriatric care than of the participants. Those who refused did not differ from the participants for the above mentioned characteristics.

Ninety one subjects had an MMSE score $<24$ points, of whom 77 were interviewed in phase II; 13 subjects refused participation and one subject moved and could not be traced (response 85\%) (figure). In this group 43 cases of dementia were diagnosed by GMSA(3)/AGECAT.

Of the random sample of subjects with an MMSE score $\geqslant 24(n=55)$ seven subjects refused to take part in the second phase (response $87 \%$ ) (figure). In those who were interviewed ( $n=48)$, two cases of dementia were detected. Their MMSE scores were respectively 24 and 26 .

\section{INCIDENCE OF DEMENTIA}

In total 45 cases of dementia were diagnosed by AGECAT in the second phase participants ( $n$ $=125$ ). The table gives the crude results of phase II, the estimation of the number of dementia cases in the initial group $(n=224)$, and the observed person-years at risk. The incidence rate of dementia was 6.9 per 100 person-years at risk $(95 \%$ confidence interval (95\% CI) $4 \cdot 8-9 \cdot 1$ ) in the whole age group. Numbers in the separate age groups were rather low, so that no incidence per age group was calculated. In women the incidence of dementia was 8.9 per 100 person-years at risk (95\% CI $5 \cdot 9-11.9$ ), in men $2 \cdot 7$ per 100 person-years at risk (95\% CI 0.5-4.9).

\section{Discussion \\ METHODS}

In this incidence study a two wave design was used in which prevalent cases of dementia were detected in the first wave of the study (December 1986-March 1989). Cases were found with a two stage study design with a screening and a diagnostic phase. Consequently cases missed by the screening method in the prevalence study (those with an MMSE score $>23$ points) will be included as incidence cases in the present study. It has been estimated by O'Connor et $\mathrm{al}^{13}$ that in an elderly population (75 years and older) $16 \%$ of those scoring 24 points and $10 \%$ of those scoring 25 points might have been demented. This might be balanced, however, by the fact that in our study only the "serial sevens" item of the MMSE has been used without spelling the word "world" backwards; the "serial sevens" are more difficult and scores are shifted downward resulting in a higher sensitivity at the cut off score of $23 / 24 .{ }^{14}$

The mean duration of follow up has been $4 \cdot 1$ years. Although this has affected the reliability in a positive way (sufficient number of incident cases), it has also caused loss to follow up due to death. Considering that those who died before follow up were older, had a lower median MMSE score, and were more often indicated for psychogeriatric care during follow up, selective loss of incident cases of dementia may have occurred, leading to an underestimation of the incidence.

\section{FINDINGS}

In our study the estimated incidence of dementia was $6 \cdot 9 / 100$ person-years. In other population studies which included sufficient subjects of 85 years and over the incidence rates were of the same order $\left(6 \cdot 0,,^{15} 8 \cdot 4,{ }^{16}\right.$ $\left.10 \cdot 5^{17}\right)$.

In these studies the rates showed a consistent increase with age. The increasing prevalence of dementia with age together with a mortality which is twice as high in the demented elderly ${ }^{18}$ — thus, reducing the prevalence rate-already pointed to high incidence in the oldest old. It is important, however, to know its real magnitude to be able to predict the number of cases that can be expected in the next decades when the oldest old will constitute a significant part of the population.

When no major change occurs in the mortality of men and women the oldest old will consist mainly (70-80\%) of women, as now. In this respect the finding of a much higher incidence rate of dementia in women is very important, especially while women in this age group are much more likely to live alone and will be in need of care earlier in the disease. In the Leiden 85 plus prevalence study also a higher prevalence rate for women than men has been found $(24 \% v 18 \%$ ), but it was not clear whether this was caused by a lower mortality among the female participants or by a higher incidence. Comparison with other studies shows that Paykel et al ${ }^{16}$ have found the same difference in rates between men and women ( 2.7 for men and 10.6 for women). In the Icelandic study ${ }^{17}$ no difference was found and in the study of Aronson et al ${ }^{15}$ men tended to have higher rate $(7 \cdot 2 v 5 \cdot 3, \mathrm{NS})$. In the last study women had a higher incidence between the ages 75 to 84 years.

An important factor when comparing incidence in men and women from different populations is the unknown selection that took place in both the male and female cohort before the age of 85 years. The causes of death in the respective cohort may be influenced by differences in the socioeconomic 
background, the lifestyle or the health care system, the influences of which may affect men and women differently. In this respect the prevalence study of Skoog et $a l^{19}$ is of interest. It was found that, by contrast with studies in younger age groups, among 85 year olds vascular dementia $(47 \%)$ had a higher prevalence than Alzheimer's disease (43\%). So in the very old vascular disease may play an important part in the aetiology of the dementia syndrome. It could be possible that women are more affected by this due to differential survival (men die from their severe cardiovascular disease). It has been shown in a study of subjects aged 75 to 85 years that women with a history of myocardial infarction were five times more prone to develop dementia than those without a history of myocardial infarction; this was not true for men. ${ }^{20}$ More sex specific data concerning the incidence and the aetiology of dementia in the oldest old are needed. Future studies should also try to elucidate the causes of death in both men and women of the reference cohort during the decades before the study.

If it is true that the increase in the incidence of dementia with age is due to the occurrence of vascular dementia this gives hope for prevention of dementia in old age by preventing vascular disease. On the other hand, the better care for survivors of stroke or myocardial infarction could cause a further increase in the incidence of dementia.

This study was supported by a grant from the "Hersenstichting Nederland" and by the Dutch Ministry of Welfare, Health and Cultural Affairs. The Leiden 85-plus study was at that time supported by the National Institute of Health, USA (No AG 06354)

1 Jorm AF, Korten AE, Henderson AS. The prevalence of dementia: a quantitative integration of the literature. Acta Psychiatr Scand 1987;76:465-79.
2 Hofman A, Rocca WA, Brayne C, et al. The prevalence of dementia in Europe: a collaborative study of 1980-1990 dindings. Int $\mathcal{F}$ Epidemiol 1991;20:736-48.

3 Heeren TJ, Lagaay AM, Hijmans W, Rooijmans HGM Prevalence of dementia in the 'oldest old' of a dutch Prevalence of dementia in the 'oldest old'
community. F Am Geriatr Soc 1991;39:755-9.

4 Heeren TJ, Hemert AM van, Lagaay AM, Rooijman HGM. The general population prevalence of nonorganic psychiatric disorders in subjects aged 85 and over. Psychol Med 1992;22:733-8.

5 Folstein MF, Folstein SE. "Mini-mental state". A practical method for grading the cognitive state of patients for the clinician. F Psychiatr Res 1975;12:189-98.

6 Tombaugh TN, McIntyre NJ. The mini-mental state examination: a comprehensive review. $7 \mathrm{Am}$ Geriatr Soc 1992:40:922-35.

7 Goldberg DP. The detection of psychiatric illness by questionnaire. London: Oxford University Press, 1972

8 Hooijer C, Jonker C, Dewey ME, Tilburg W van, Copeland JRM. A standardized interview for the elderly (GMS): reliability studies comparing the Dutch language version with the original. Int $\mathcal{f}$ Geriatr Psychiatry (Neurol 1991;6:71-9.

9 American Psychiatric Association. Diagnostic and statistic manual of mental disorders. 3rd ed. Washington DC: APA, 1980

10 Hughes CP, Berg L, Danziger WL, Coben LA, Martin RL. A new clinical scale for the staging of dementia. $B r F$ Psychiatry 1982;140:566-72.

11 Copeland JRM, Dewey ME, Griffith-Jones HM. Psychiatric case nomenclature and a computerised diagnostic system for elderly subjects: GMS and AGECAT. Psychol Med 1986;16:89-99.

12 Copeland JRM, Dewey ME, Henderson AS, et al. The geriatric mental state (GMS) used in the community: geriatric mental state (GMS) used in the community:
replication studies of the computerized diagnosis AGEreplication studies of the computerized
CAT. Psychol Med 1988;18:219-23.

13 O'Connor DW, Pollitt PA, Hyde JB, et al. The reliability and validity of the mini-mental state in a British community survey. $\mathcal{f}$ Psychiatr Res 1989;23:87-96.

14 Brayne C, Calloway P. The case identification of dementia in the community: a comparison of methods. International foumal of Geriatric Psychiatry 1990;5:309-16.

15 Aronson MK, Ooi WI, Geva DL, et al. Dementia; agedependent incidence, prevalence and mortality in the old old. Arch Intern Med 1991;151:989-92.

16 Paykel ES, Brayne C, Huppert FA, et al. Incidence of dementia in a population older than 75 years in the United Kingdom. Arch Gen Psychiatry 1994;51:325-32.

17 Magnusson H. Mental health of octogenarians in Iceland. Acta Psychiatr Scand 1989;79:59-66.

18 Heeren TJ, Hemert AM van, Rooijmans HGM. A community based study of survival in dementia. Acta munity based study of survival

19 Skoog I, Nilsson L, Palmertz B, Andreasson L, Svanborg A. A population-based study of dementia in 85-yearolds. N Engl F Med 1993;328:153-58.

20 Aronson MK, Ooi WL, Morgenstern $\mathrm{H}$, et al. Women, myocardial infarction, and dementia in the very old. Neurology 1990;40:1102-6. 